Original Article

\title{
The effect of a postural exercise program on muscle power in Italian high school students
}

\author{
Saverio Sabina, MSc ${ }^{1)^{*} a}$, Maria Rosaria Tumolo, MSc ${ }^{2) a}$, Pierpaolo Mincarone, PhD ${ }^{2}$, \\ Pasquale De Micheli, MSc ${ }^{3)}$, Luca Bertone, MD ${ }^{4}$, Chiara Salerno, MD $^{5)}$, \\ Antonella Bodini, $\mathrm{PhD}^{6}$ ), Roberto Guarino, $\mathrm{HSD}^{1)}$, Giuseppe Ponzini, $\mathrm{MSc}^{2}$, \\ Riccardo Colella, PhD ${ }^{1)}$, Carlo Giacomo Leo, $\mathrm{PhD}^{1)}$, Vincenzo Canali, MSc ${ }^{7)}$ \\ 1) National Research Council, Institute of Clinical Physiology, Branch of Lecce: clo Campus Ecotekne \\ via Monteroni, 73100 Lecce, Italy \\ 2) National Research Council, Institute for Research on Population and Social Policies, Research Unit \\ of Brindisi, Italy \\ 3) High School "Egidio Lanoce", Italy \\ 4) "Valle d'Itria" Hospital Unit, Complex Operational Unit of Medicina, Italy \\ 5) District Rehabilitation Presidium, Italy \\ 6) National Research Council, Institute for Applied Mathematics and Information Technologies \\ "Enrico Magenes", Branch of Milan, Italy \\ 7) Postura e Sport SRL, Italy
}

\begin{abstract}
Purpose] The present study aimed to investigate the effect of an innovative postural program (the Canali Postural Method, CPM) on muscle power in Italian high school students. It is note that deficits in posture control may, in long term, generate posture weakness as early as childhood and adolescence. Postural programs based on stretching and strengthening exercises can remove these deficits and can be framed in general physical or sport activities. [Participants and Methods] Thirty-four students completed a 8-week postural program. The intervention, consisting of stretching and muscle activation exercises, was integrated in physical education lessons. For the evaluation of the effect of CPM program, we have used the countermovement jump (CMJ), a simple and versatile test that measures muscle power. [Results] The CPM program resulted in significantly increased vertical jump height of the students. The average difference between Initial and Final CMJ was $2.1 \mathrm{~cm}$. [Conclusion] This finding indicates the benefic effect of this new postural program on physical performance in the youth. Further randomized control trials should be conducted to evaluate CPM long-term implications in the prevention of posture weaknesses and its inclusion in the regular school curriculum.

Key words: Postural training, Muscle power, Countermovement jump
\end{abstract}

(This article was submitted May 16, 2020, and was accepted Jul. 9, 2020)

\section{INTRODUCTION}

Posture is the result of a complex interaction of the skeleton, musculature, and central nervous system ${ }^{1)}$. Posture control, defined as an isometric and motor behavior representing a stable starting point for the execution of movements ${ }^{2)}$, is a key contributor to physical performance for mastering daily routine tasks and athletic activities ${ }^{3,4)}$. Deficits in posture control may, in the long term, generate posture weakness (e.g., lumbar hyperlordosis, hunchback, protracted shoulders, and protruded head) as early as childhood and adolescence ${ }^{5)}$, with a reported prevalence of around $22-65 \%$ depending on its exact prob-

aThese authors contributed equally to this work. *Corresponding author. Sabina Saverio (E-mail: sabina@ifc.cnr.it) (C2020 The Society of Physical Therapy Science. Published by IPEC Inc.

(c) (1) $\odot$ This is an open-access article distributed under the terms of the Creative Commons Attribution Non-Commercial No Deriva-

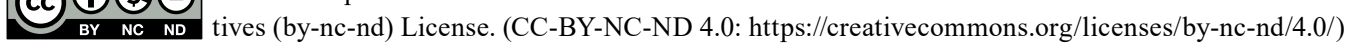


lematic $^{6-8)}$. Posture weaknesses may lead to a biomechanically unfavorable strain of tendons and joints, and asymmetrical muscle activity generating potential muscular problems ${ }^{9}$.

Postural programs systematically remove deficits in posture control and can be framed in general physical or sport activities $^{10,11)}$. Consequently, such programs could be joined to the standardized school physical education curriculum as a preventive and community approach, instead of targeting small groups of subjects with pain and postural problems, as the U.S. Department of Labor, in its handbook of postural exercises for schools and teachers of physical education, has recommended since $1926^{12,13)}$. Resistance and stretching as well as balance training programs during physical education lessons could have the potential to improve postural control ${ }^{14,15)}$.

In the last few years, an innovative postural method based on gymnastic exercises, the Canali Postural Method (CPM), has proposed to reduce deficits in postural control through the activation of pelvic and shoulder stabilizer muscles with the contemporary rebalancing of their collaborative muscle structures ${ }^{16)}$.

Postural programs are based on stretching and strengthening exercises and hence affect muscle power (muscle length and strength contributed to muscle power), ${ }^{17}$ ) which can be used as an indirect measure of their efficacy.

The purpose of this study was to investigate the effect of a postural program based on the CPM on muscle power in Italian high school students. The program, also suited for adolescents with a non-elite sporting profile, was focused on the stabilization of the trunk, and the mobilization improvement of the scapulohumeral, coxofemoral and ankle joints.

For a quantitative assessment of the program's efficacy, we adopted the countermovement jump (CMJ), a simple and versatile test that measures muscle power ${ }^{18)}$.

\section{PARTICIPANTS AND METHODS}

The study involved 41 students from the Technical Chemical, Environmental and Health sectors of High School "Egidio Lanoce" in Maglie (Lecce, Italy), of which $34(16.7 \pm 1.5$ years of age, weight $67.5 \pm 19.2 \mathrm{~kg}$, height $167.4 \pm 9.9 \mathrm{~cm})$ completed the required minimum number of workout sessions. The participants were considered eligible unless they had medical contraindications for physical activity and were undergoing long-term pharmacological therapy during the study period. They were excluded if they did not perform at least six of the eight planned workout sessions.

The local ethics committee decided that formal approval was not necessary, as the risk incurred by the study was considered low. The participants received a full explanation of the content of the research, and written informed consent was obtained from adult students and parents/legal guardians prior to inclusion in accordance with the ethical standards of the Declaration of Helsinki. Additional consent was granted by one individual to include her photos in this publication to demonstrate the exercises.

As a necessary introductory activity, discussions with students were promoted on the importance of a physically active life and consideration of their habits and extent of enjoyment. Moreover, elements of anatomy and a background on posture were also provided.

The intervention program was developed and supervised by two authors who are qualified trainers with CPM certifications (SS, LB), in collaboration with the inventor of the method (VC).

The program combines the activation of stabilizer muscles with the reduction of muscle peripherical resistances ${ }^{16)}$. More specifically, the intervention alternated three stretching and three muscle activation exercises all executed without the use of weights. Table 1 describes the detailed sequence providing the objective, the normal execution and the facilitation (easy starting execution) for each exercise, included for participants with a resistance on the posterior muscle chain (mainly due to hip extensor muscles rigidity) which, at the beginning, cannot maintain the position provided for the normal execution.

The intervention period lasted eight weeks and involved eight workout sessions (one per week). Stretching and muscle activation exercises lasted $10 \mathrm{~s}$ and $20 \mathrm{~s}$, respectively, for the first two weeks. Muscle activation was incremented weekly for up to $40 \mathrm{~s}$. The entire battery of exercises was executed each time repeatedly for 30'. In the remaining 30', and in the second of the two weekly hours spent on physical activity at school, students performed the ordinary program. Students were asked not to change their usual physical activity outside of school during the study.

The outcome measured was the variation in vertical jump height for CMJ after the intervention. For the CMJ preparation, participants were instructed to perform, starting from a standing position, a downward movement immediately followed by a rapid upward movement ${ }^{19)}$. Before the test, all students performed a five-minute warm-up program consisting of the execution of the exercises described for the intervention.

CMJ was measured with the inertial sensor system Gyko by Microgate (Bolzano, Italy). The device contains a threedimensional accelerometer, gyroscope, and magnetometer, weighs $35 \mathrm{~g}$ and has the following dimensions: $50 \times 70 \times 20 \mathrm{~mm}$. During the assessment, information was transferred to a personal computer using Bluetooth 4.0 and stored using the Microgate proprietary software 20,21$)$

Descriptive analysis consisted of mean and standard deviation for all participants data. The Shapiro-Wilks test has been used to check gaussianity, and post-intervention has been compared to pre-intervention by either a t-test or the non parametric Wilcoxon test, according to a gaussianity check. 
Table 1. Intervention program exercises

\begin{tabular}{lll}
$\begin{array}{l}\text { Execution } \\
\text { order }\end{array}$ & Exercises \\
\hline 1 & $\begin{array}{l}\text { Exercise: } \\
\text { Objective: }\end{array}$ & To increase posterior muscle chain extension by pelvic anteversion. \\
Note: $\quad$ & $\begin{array}{l}\text { In the easy starting execution, the exclusion of the scapular stabilizers decreases the resistance of the posterior } \\
\text { muscle chain. }\end{array}$ \\
& Normal execution
\end{tabular}

$2 \quad$ Exercise: N. 23b (Canali, 2014)

Objective: To activate the abdominal muscles from a supine position using an elastic load (auxologic load).

Note: $\quad 1$. The exercise should be executed with the legs perpendicular to the ground; 2 . The load lever can be decreased in the easy starting execution if it is in contrast with the activation of the abdominal muscles; 3. The resistance of the posterior muscle chain can be decreased by lifting the pelvis if the subject cannot kept the legs perpendicular to the ground; 4. In the normal execution, the activation of the abdominal muscles is enhanced by using the scapular stabilizers that must be excluded in the easy starting execution to decrease the resistance of the posterior muscle chain.

Normal execution

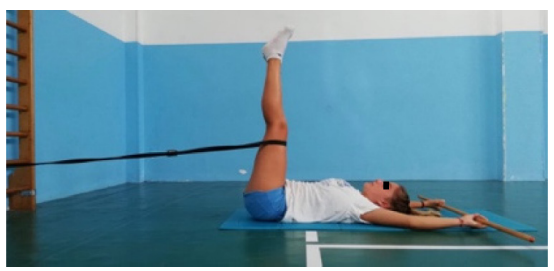

Easy starting execution

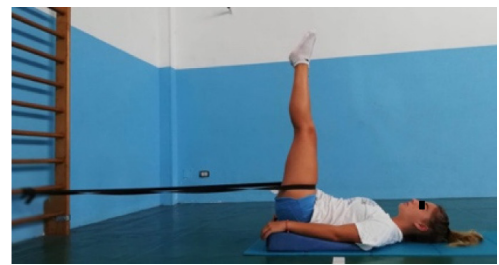

$3 \quad$ Exercise: $\quad$ N. 3 (Canali, 2017)

Objective: To increase anterior muscle chain extension by correctly retracting the rib cage and extending the pelvis in order to fix the spine.

Note: $\quad$ 1. Different levels of the rib cage retraction and pelvis extension determine the difficulty of the exercise;

2. The exercise is repeated for each leg.

Normal execution

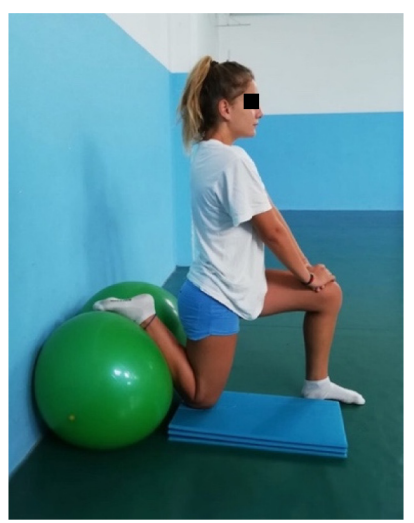


Table 1. Continued

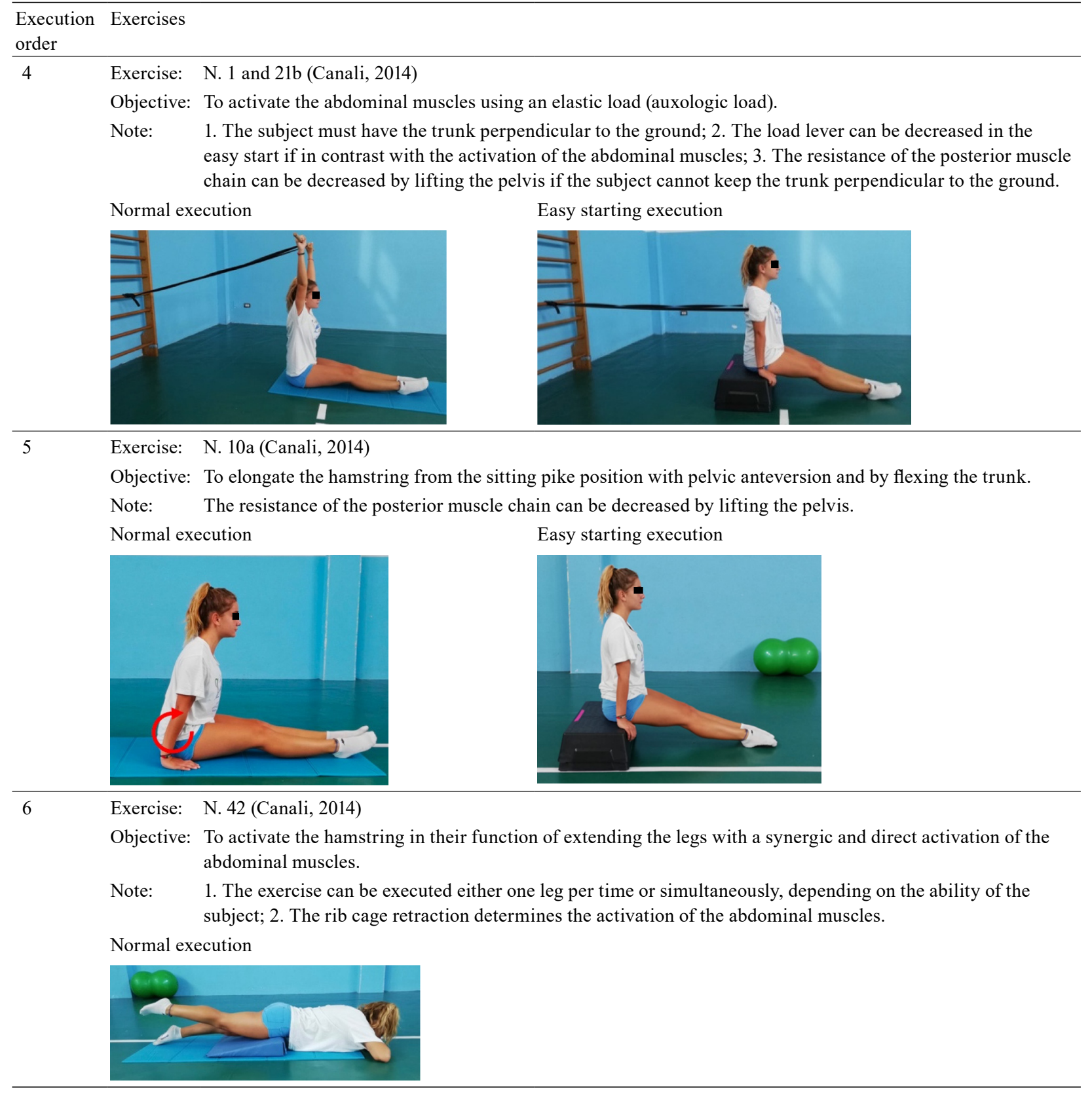

\section{RESULTS}

The final cohort consisted of thirty-four students; seven did not completed the required minimum number of workout sessions. The characteristics of the cohort were presented in Table 2.

Descriptive statistics for the pre- and post-intervention data for the CMJ can be found in Table 3, in which was also reported the number of the workout sessions performed by the subjects. Gaussianity was not rejected $(p=0.10)$ and the difference between final and initial CMJ has been found to be significantly different from 0 and positive, based on the t-test $(\mathrm{p}<0.0015)$.

\section{DISCUSSION}

The purpose of this study was to examine the effect of a postural program on muscle power measured through the CMJ in Italian high school students.

To the authors' knowledge, very few studies ${ }^{14,15)}$ have examined the efficacy and feasibility of postural programs per- 
Table 2. Characteristics of the study participants

\begin{tabular}{lc}
\hline Characteristics & Study cohort $(\mathrm{N}=34)$ \\
\hline Gender, males [N] (\%) & $15(44.1 \%)$ \\
Age [years], mean \pm SD & $16.7(1.5)$ \\
Weight [kg], mean \pm SD & $67.5(19.2)$ \\
Height [cm], mean \pm SD & $167.4(9.9)$ \\
Involved in sports with jumps [N] (\%) & $12(35.3 \%)$ \\
\hline
\end{tabular}

Table 3. Participation rates and performances before and after the intervention program

\begin{tabular}{lc}
\hline Number of subjects with 8 workout sessions, [N] (\%) & $15(44.1 \%)$ \\
Number of subjects with 7 workout sessions, [N] (\%) & $16(47.1 \%)$ \\
Number of subjects with 6 workout sessions, [N] (\%) & $3(8.8 \%)$ \\
Initial CMJ [cm], mean \pm SD & $22.70(5.9)$ \\
Final CMJ [cm], mean \pm SD & $24.84(6.9)$ \\
Difference between Initial and Final CMJ [cm], mean \pm SD & $2.1(3.5)^{*}$ \\
\hline
\end{tabular}

$\mathrm{N}$ : participants; CMJ: countermovement jump.

$* \mathrm{p}<0.0015$.

formed at school, despite the school has been recognized as an important institution for the promotion of physical activity ${ }^{22)}$. Only one study ${ }^{14)}$ considered the effects of the program on CMJ. Moreover, the school, since 1926 ${ }^{12,13)}$, was suggested as the place where developing postural programs for preventive interventions.

In our study, we used a set of exercises from an innovative postural method based on a combination of stretching and strength exercises that could determine mechanical changes in participants by improving their flexibility and explosive power after the training $\left.{ }^{15}, 23\right)$. The results showed a significant difference in students' performance after an eight-week postural program, suggesting an increase in muscle power. The present finding is in accordance with Granacher et al., in which a balance training of comparable duration in high school students resulted in an increase in vertical jump height, although not a statistically significant one ${ }^{14}$.

The recorded improvement in jump height, not attributable to direct jump ability training (which was not included in the program), could be due to adaptive neuromuscular mechanisms, as suggested by Taube and colleagues ${ }^{24)}$, probably addressed in our postural program, but not verified due to the methodological limitations of the study.

Due to time constraints, the school environment does not easily allow the personalization of interventions. One aspect of CPM, not applicable to this study, is a preliminary postural evaluation of the subject, allowing for a personalized intervention. According to this evaluation, qualitative and targeted-to-the-cause exercises are selected to act on the key concepts of the $\mathrm{CPM}$, such as the rebalancing of the flexion-extension relationships of collaborative muscles with the objective of reducing or resolve the cause of the postural problems ${ }^{16}$.

Limitations of this study should be acknowledged. The lack of a control group and the use of the CMJ as a proxy for the evaluation of postural intervention were considered weaknesses in this study.

Since muscle power/strength represent important components of physical fitness and injury prevention ${ }^{25,26)}$, and based on our preliminary results, further well-designed randomized control trials should be conducted, also with full CPM application, in order to assess its long-term implications in the prevention of posture weaknesses and, hence, evaluate its inclusion in the regular school curriculum. In this regard, according to Qiu et al. ${ }^{27)}$, the use of properly designed wearable devices equipped with accelerometers, gyroscopes, magnetometers, and other sensors for human movement estimation could help in accurate evaluation of specific postural interventions in the future.

\section{Conflict of interest}

The authors have no conflicts of interest to declare, with the only exception of Vincenzo Canali, the owner of Postura e Sport SRL, who uses the Canali Postural Method, investigated in the paper, for business interests in his company. Although Vincenzo Canali contributed to the study design and to the selection of the postural program exercises, he did not participate in any way in study execution in order to exclude any potential bias in the assessment and in the intervention phases.

\section{ACKNOWLEDGMENT}

We would like to thank the High School "Egidio Lanoce" in Maglie (Lecce, Italy) for supporting us during this study. 


\section{REFERENCES}

1) Assaiante C, Mallau S, Viel S, et al.: Development of postural control in healthy children: a functional approach. Neural Plast, 2005, 12: 109-118, discussion 263-272. [Medline] [CrossRef]

2) Carini F, Mazzola M, Fici C, et al.: Posture and posturology, anatomical and physiological profiles: overview and current state of art. Acta Biomed, 2017, 88 : 11-16. [Medline]

3) Punakallio A: Balance abilities of different-aged workers in physically demanding jobs. J Occup Rehabil, 2003, 13: 33-43. [Medline] [CrossRef]

4) Santos L, Fernández-Río J, Fernández-García B, et al.: Effects of slackline training on postural control, jump performance, and myoelectrical activity in female basketball players. J Strength Cond Res, 2016, 30: 653-664. [Medline] [CrossRef]

5) Ludwig O, Kelm J, Hammes A, et al.: Targeted athletic training improves the neuromuscular performance in terms of body posture from adolescence to adulthood-long-term study over 6 years. Front Physiol, 2018, 9: 1620. [Medline] [CrossRef]

6) Kratenová J, Zejglicová K, Malý M, et al.: Prevalence and risk factors of poor posture in school children in the Czech Republic. J Sch Health, 2007, 77: 131-137. [Medline] [CrossRef]

7) Lee JH: Effects of forward head posture on static and dynamic balance control. J Phys Ther Sci, 2016, 28: 274-277. [Medline] [CrossRef]

8) Wirth B, Knecht C, Humphreys K: Spine Day 2012: spinal pain in Swiss school children—epidemiology and risk factors. BMC Pediatr, 2013, 13: 159. [Medline] [CrossRef]

9) Bruno AG, Anderson DE, D'Agostino J, et al.: The effect of thoracic kyphosis and sagittal plane alignment on vertebral compressive loading. J Bone Miner Res, 2012, 27: 2144-2151. [Medline] [CrossRef]

10) Kim D, Cho M, Park Y, et al.: Effect of an exercise program for posture correction on musculoskeletal pain. J Phys Ther Sci, 2015, 27: 1791-1794. [Medline] [CrossRef]

11) Byun S, An C, Kim M, et al.: The effects of an exercise program consisting of taekwondo basic movements on posture correction. J Phys Ther Sci, 2014, 26: 1585-1588. [Medline] [CrossRef]

12) Armin K, Leah T: Posture exercises: a handbook for schools and for teachers of physical education. 2018

13) Armin K, Leah T: Posture exercises: a handbook for schools and for teachers of physical education. 1926.

14) Granacher U, Gollhofer A, Kriemler S: Effects of balance training on postural sway, leg extensor strength, and jumping height in adolescents. Res Q Exerc Sport, 2010, 81: 245-251. [Medline] [CrossRef]

15) Ruivo RM, Carita AI, Pezarat-Correia P: The effects of training and detraining after an 8 month resistance and stretching training program on forward head and protracted shoulder postures in adolescents: randomised controlled study. Man Ther, 2016, 21: 76-82. [Medline] [CrossRef]

16) Canali V: Posture e sport. Perugia: Calzetti \& Mariucci editori, 2014

17) Josephson RK: Dissecting muscle power output. J Exp Biol, 1999, 202: 3369-3375. [Medline]

18) Gomez-Bruton A, Gabel L, Nettlefold L, et al.: Estimation of peak muscle power from a countermovement vertical jump in children and adolescents. J Strength Cond Res, 2019, 33: 390-398. [Medline] [CrossRef]

19) Van Hooren B, Zolotarjova J: The difference between countermovement and squat jump performances: a review of underlying mechanisms with practical applications. J Strength Cond Res, 2017, 31: 2011-2020. [Medline] [CrossRef]

20) Hamersma DT, Hofste A, Rijken NH, et al.: Reliability and validity of the Microgate Gyko for measuring range of motion of the low back. Musculoskelet Sci Pract, 2020, 45: 102091. [Medline] [CrossRef]

21) Lesinski M, Muehlbauer T, Granacher U: Concurrent validity of the Gyko inertial sensor system for the assessment of vertical jump height in female sub-elite youth soccer players. BMC Sports Sci Med Rehabil, 2016, 8: 35. [Medline] [CrossRef]

22) Wechsler H, Devereaux RS, Davis M, et al.: Using the school environment to promote physical activity and healthy eating. Prev Med (Baltim), Academic Press Inc., 2000, p 31.

23) Muehlbauer T, Gollhofer A, Granacher U: Associations between measures of balance and lower-extremity muscle strength/power in healthy individuals across the lifespan: a systematic review and meta-analysis. Sports Med, 2015, 45: 1671-1692. [Medline] [CrossRef]

24) Taube W, Gruber M, Gollhofer A: Spinal and supraspinal adaptations associated with balance training and their functional relevance. Acta Physiol (Oxf), 2008, 193: 101-116. [Medline] [CrossRef]

25) Wang HK, Chen CH, Shiang TY, et al.: Risk-factor analysis of high school basketball-player ankle injuries: a prospective controlled cohort study evaluating postural sway, ankle strength, and flexibility. Arch Phys Med Rehabil, 2006, 87: 821-825. [Medline] [CrossRef]

26) Fousekis $\mathrm{K}$, Tsepis E, Poulmedis $\mathrm{P}$, et al.: Intrinsic risk factors of non-contact quadriceps and hamstring strains in soccer: a prospective study of 100 professional players. Br J Sports Med, 2011, 45: 709-714. [Medline] [CrossRef]

27) Qiu S, Wang H, Li J, et al.: Towards wearable-inertial-sensor-based gait posture evaluation for subjects with unbalanced gaits. Sensors (Switzerland), MDPI AG, 2020, 20: pii: E1193. 